\title{
Laparoscopic cholecystectomy: One surgeon's experience in 100 consecutive cases
}

IVAN J POKORNY MRCS LRCP FRCS(Ed) FACS FRCSC

IJ POKORNY. Laparoscopic cholecystectomy: One surgeon's experience in 100 consecutive cases. Can J Gastroenterol 1994;8(4):277-278. Initial 100 consecutive laparoscopic cholecystectomies performed by one surgeon were studied prospectively. The standard technique was modified in that the gallbladder removal was accomplished through the upper epigastric incision; there was no need to change the location of the camera. The conversion rate to open cholecystectomy was $2 \%$. There were no major complications and no mortality. Minor complications occurred in $9 \%$ of the patients. Laparoscopic cholecystectomy can be performed safely in a community hospital setting. Simplified technique of gallbladder extraction is recommended.

Key Words: Gallstones, Laparoscopy, Surgery

\section{Cholécystectomie laparoscopique : expérience de 100 cas} consécutifs effectués par un chirurgien

RÉSUMÉ : Les 100 premières cholécystectomies laparoscopiques effectuées par un chirurgien ont été étudiées de façon prospective. La technique standard a été modifiée en ce sens que l'ablation de la vésicule biliaire a été faite par l'incision épigastrique supérieure, mais il n'a pas été nécessaire de modifier la localisation de la caméra. Le taux de conversion à la cholécystectomie ouverte a été de $2 \%$. Aucune complication importante ni aucun cas de mortalité ne sont survenus. Des complications mineures sont survenues chez $9 \%$ des patients. Une cholécystectomie par laparoscopie peut être effectuée en toute sécurité dans le contexte d'un hôpital communautaire. La technique simplifiée de cholécystectomie est recommandée.
A FTER INITIAL SCEPTICISM, LAP. aroscopic cholecystectomy is becoming the method of choice in the surgical treatment of symptomatic gallbladder disease. Avoidance of abdominal incision, particularly in the rectus muscle and fascial transection, as well as relatively minimal intraperitoneal visceral manipulation, seem to lead to dramatically improved postoperative recovery.

Laparoscopic cholecystectomy requires special training and experience, but can be mastered by most general surgeons performing biliary surgery.

As in other procedures, surgeon per- formance improves with increased experience. It is accepted that formal training, including an accredited course as well as initial supervised clinical experience, is necessary. Experience with colonoscopic polypectomies, with the use of the video monitor, is particularly helpful in acquiring skills necessary to perform laparoscopic cholecystectomy.

The standard method of laparoscopic cholecystectomy was modified in that the extraction of the gallbladder is carried out through the upper midline epigastric incision without changing the location of the camera at the umbilicus; this simplifies the procedure and does not lead to increased morbidity.

\section{PATIENTS AND METHODS}

All patients referred for surgical treatment of symptomatic cholelithiasis were considered, except for those with contraindications: choledocholithiasis and history of extensive upper abdominal surgery. Six patients had intraoperative evidence of acute cholecystitis. The marked thickness of the gallbladder wall, inflammatory adhesions around the gallbladder and congestion made the procedure more difficult. In these cases, the procedure required gradual careful dissection with mobilization of the adhesions and meticulous dissection of the cystic artery and cystic duct before clipping these structures. Although laparoscopic chol- 
ecystectomy is undoubtedly more difficult in acute cholecystitis, it can be performed safely in most cases. Cholangiograms were not done routinely. Patients were evaluated clinically with liver function tests, ultrasound of the common bile duct and, in two cases, preoperative endoscopic retrograde cholangiopancreatography (ERCP).

\section{RESULTS}

One hundred patients underwent laparoscopic cholecystectomy without major complications. Complications encountered were pneumothorax, one patient; subhepatic hematoma, four; pneumonia, one; alcoholic withdrawal, two; and bile collection, one. The conversion rate was $2 \%$. A drain was used in six cases (JVAC Quadlumen 1/8 inch). Indications for drainage were difficulty dissecting in acute cholecystitis and increased oozing from gallbladder bed of blood or bile.

The postoperative stay ranged from one to 30 days. Operating time ranged from 30 to 360 mins (average 55 mins).

\section{DISCUSSION}

Laparoscopic cholecystectomy was adopted for elective cholecystectomy. The procedure was readily learned and after the first few cases generally became easy to perform. As with all biliary surgery, careful dissection and recognition of anatomical structures in the operative area are essential to avoid potentially serious complications. The patients were also happy with the results - they recovered much faster, left the hospital earlier and returned to work after two to three weeks.

One case of postoperative pneumo-

\section{BIBLIOGRAPHY}

Bailey RW, Zucker KA, Flowers JL, Scovill WA, Graham SM, Imbembo AL. Laparoscopic cholecystectomy, experience with 375 consecutive patients. Ann Surg 1991;214:531-40.

Dion Y-M, Morin J. Laparoscopic cholecystectomy: a report of 60 cases. Can J Surg 1990;33:483-6. thorax required intercostal tube insertion. The etiology remains unexplained, but the possibilities considered include spontaneous rupture of the lung bulla, instrumental injury and pleuroperitoneal communication. The patient made prompt uncomplicated recovery and was discharged four days after surgery. One patient required open drainage of subhepatic collection of bile due to a slipped clip from the cystic duct. Bile collection was drained and cystic duct was ligated. Further recovery was uneventful.

The four cases of subhepatic hematoma were diagnosed clinically and confirmed by ultrasound. They were treated conservatively and all resolved spontaneously. This complication can be avoided by careful attention to and the use of suction drainage when indicated. Surgical drainage is recommended when doubt exists as to the completeness of hemostasis in gangrenous cholecystitis or if there is a possibility of bile leakage from the liver bed.

Alcoholic withdrawal and hepatic dysfunction related to alcoholism were responsible for the extended hospital stay in two cases. Both patients made full recovery and were discharged after management of liver complications.

Most patients may be discharged on the first or second postoperative day. The minimum of $24 \mathrm{~h}$ in hospital postoperative observation is advisable. When choledocholithiasis is suspected preoperatively, it is very helpful to obtain ERCP. If feasible, endoscopic clearance of common bile duct will permit subsequent laparoscopic cholecystectomy.

Holohan TV. Laparoscopic cholecytstectomy. Lancet 1991;338:801-3.

Peters JH, Gibbons GD, Innes JT, et al. Complications of laparoscopic cholecystectomy. Surgery 1991;110:769-71.

Russell RCG. Laparoscopic cholecystectomy. Lancet 1991;338:1074-5.
Indications for intraoperative cholangiography include history of jaundice, pancreatitis, abnormal elevation of liver function tests and abnormal dilation of common bile duct. Routine cholangiography in all cases is unnecessary.

The standard technique was modified in that the gallbladder was removed through the upper midline epigastric opening. This avoided changing the position of the camera and saved some operative time. There were no complications related to this change of technique.

Overall experience with laparoscopic cholecystectomy is very favourable. Most general surgeons would agree that it has now replaced elective open cholecystectomy. Results reported in the literature also suggest that laparoscopic cholecystectomy should be universally accepted as the method of choice for elective cholecystectomy for the appropriate indications.

\section{SUMMARY}

Laparoscopic cholecystectomy was used in the treatment of cholelithi. asis and chronic gallbladder disease in 100 consecutive cases. All procedures were done by the same surgeon in a community hospital setting. The technique of gallbladder extraction was modified in that the gallbladder was removed through the upper epigastric incision. There was no mortality and very minimal morbidity. Both patient and surgeon satisfaction indices were high. The procedure is recommended as the method of choice for gallbladder removal in the absence of contraindications.

Wetter LA, Way LW. Surgical therapy for gallstone disease.

Gastroenterol Clin North Am $1991 ; 20: 157-69$.

Wilson P, Leese T, Morgan WP, Kelly JF, Brigg JK. Elective laparoscopic cholecyslectomy for 'all-comers'. Lancet 1991;338:795-7. 


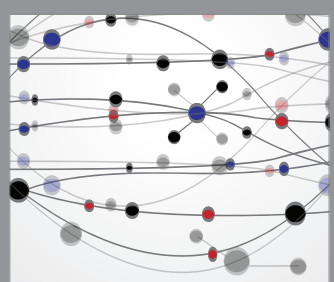

The Scientific World Journal
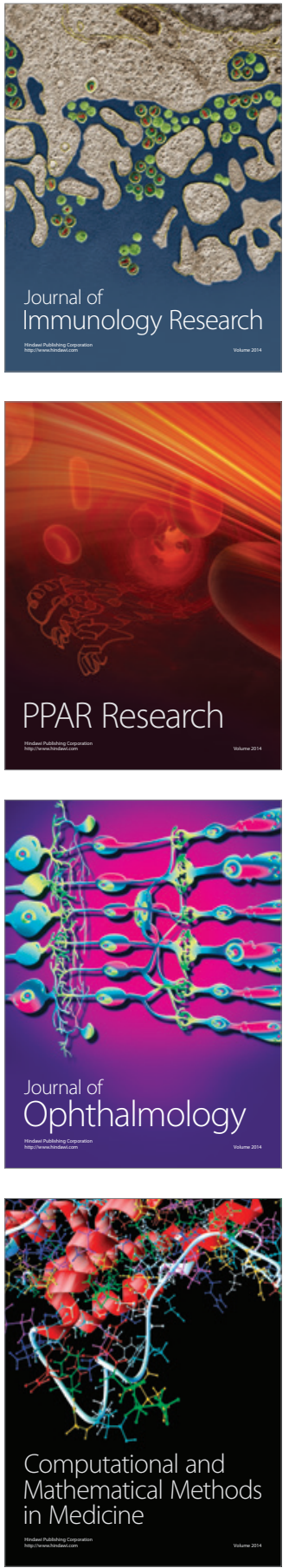

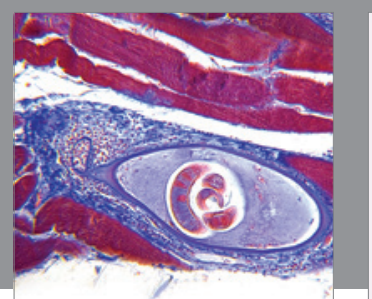

Gastroenterology Research and Practice

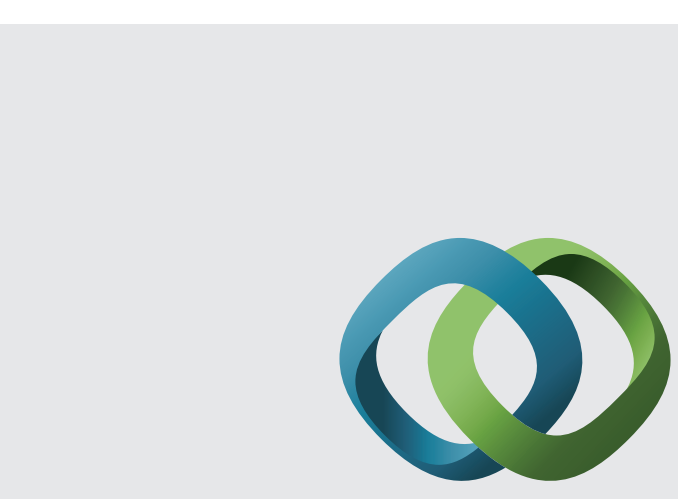

\section{Hindawi}

Submit your manuscripts at

http://www.hindawi.com
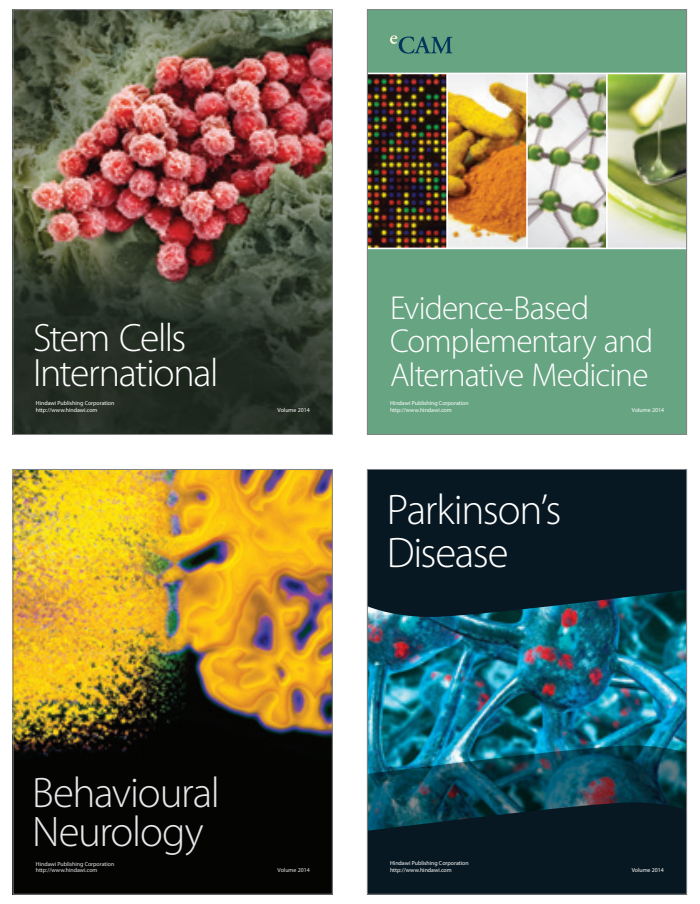
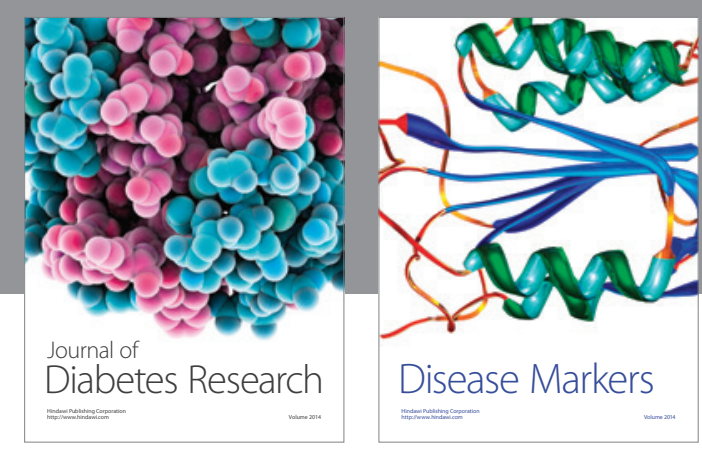

Disease Markers
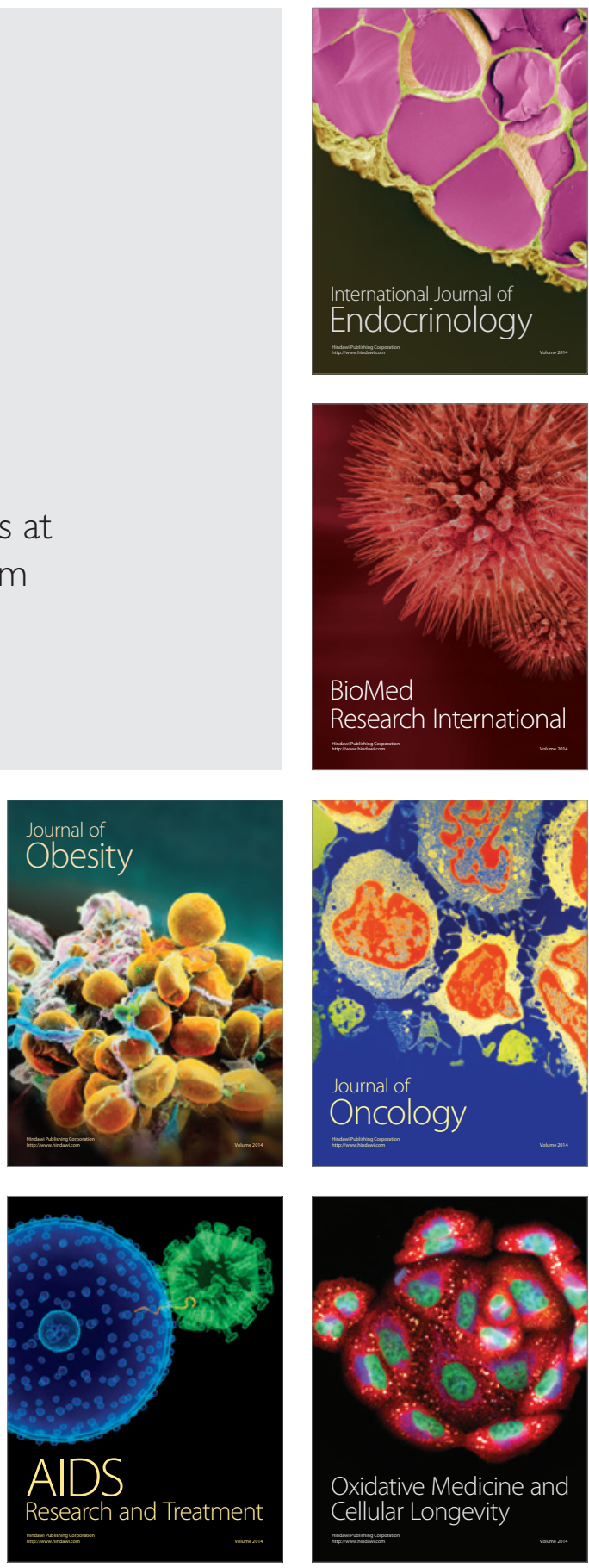